\title{
Evaluation of Long-term Skid Resistance of Asphalt Mixture with Multi-content Basic Oxygen Furnace (BOF) Steel Slag Using the Circular Vehicle Simulator (CVS)
}

\author{
Liqun $\mathrm{Hu}^{1,2}$, Shouke Wang ${ }^{1, *}$, Qiang Zhang ${ }^{1}$ \\ ${ }^{1}$ School of Highway, Chang'an University, China \\ ${ }^{2}$ Key Laboratory of Special Area Road Engineering of Ministry of Education, Chang'an University, Xi'an, Shaanxi 710064, China
}

\begin{abstract}
Long-term anti-skid performance plays a vital role on the road life cycle and driving safety. Therefore, the CVS was proposed, which can perform full-size polishing on the rutting slabs. The CVS system was used to simulate the long-term anti-skid attenuation law of five kinds of asphalt mixture with different BOF steel slag contents, and the influence of different BOF steel slag contents on the road anti-skid performance was comprehensively analyzed by using pendulum friction value. With the increase of BOF steel slag volume, the long-term anti-skid performance of asphalt mixture increases first and then decreases. Especially, the asphalt mixture with $50 \%$ BOF steel slag content has the best long-term anti-skid performance.
\end{abstract}

\section{Introduction}

Steel slag is a solid waste slag produced in steel-making process, mainly composed of silicate and oxide aggregates [1]. Steel slag is a kind of recycled material which has the potential to replace natural aggregate to prepare asphalt mixture. Adding steel slag improves the water stability, particle loss resistance and fracture energy of asphalt mixtures [2]. According to the research report of Transport Research Laboratory (TRRL), the polish value of steel slag was generally over 60 , which can be used as aggregate for wear-resistant and skid-resistant pavement. And the skid resistance attenuation rate of steel slag asphalt mixture was slower than that of basalt asphalt mixture [3]. Stock applied steel slag to gravel layer sealing and indicated that the skid resistance of steel slag was much better than that of normal gravel layer sealing [4]. Wu used steel slag as coarse aggregate in asphalt mixture to verify its feasibility, and pointed out that the asphalt mixture with steel slag had better skid resistance than ordinary basalt asphalt mixture [5]. However, there are few laboratory studies on long-term skid resistance of steel slag asphalt mixture and its attenuation law. Furthermore, the polishing devices, used to evaluate the skid resistance of asphalt mixture in laboratory, cannot simulate the polishing effect of real road surface under the vehicle load, resulting the skid resistance attenuation law of asphalt mixture has some limitations.

Early scholars and research institutes in different regions of the world developed a number of experimental instruments for simulation experiments, which have become mature up to now. Instruments that can be used to measure the polishing performance of aggregates

\footnotetext{
* Corresponding author: 2018121149@chd.edu.cn
}

mainly include the British wheel grinder, the Michigan indoor track polishing tester and the Deval polishing testing machine. And there are also many common instruments which can evaluate the anti-skid performance of the asphalt mixture, such as German Wiener/Schultz polishing machine, American NCAT polishing machine, Aachen polishing machine, South Africa MMLS and some self-modified laboratorial polishing machines [6-8]. The Wiener/Schultz polishing machine, developed by the Technical University of Berlin in Germany in the 1960s, is a typical polishing device which can not only polish the asphalt mixture, but also measure the dynamic friction coefficient of the test specimens [9]. However, the devices mentioned above use a small proportion of wheels or rubber wheels to simulate vehicle tires for loading and polishing, which has some obvious limitations compared with actual traffic conditions. Hence, the CVS was developed which can independently measure the surface functional characteristics of a large number of specimens in a single test device.

\section{Materials}

\subsection{Aggregate and binder}

Two kinds of aggregates, BOF steel slag provided by Inner Mongolia Baotou Steel Group Co., Ltd and Kundulun river granite, in China, were used to prepare mixes containing various portions of BOF steel slag. The mechanical property test results of BOF steel slag and granite are summarized in table 1 , which satisfied the requirements of the Chinese specifications [10]. BOF 
steel slag was employed in this study to replace the coarse faction of asphalt mixes. BOF steel slag was stockpiled outdoors for more than one year to expose the material to moisture from natural precipitation. The purpose of aging was to allow potential hydration and its associated expansion to take place prior to use of BOF steel slag in asphalt mixes. BOF steel slag has better soundness, polished value and abrasion resistance than granite, which was mainly due to the presence of metal oxides in BOF steel slag. A styrene-butadiene-styrene (SBS) modified asphalt binder produced by Zhongli Asphalt Co. Ltd. in Xi'an, China, was used in this study.

Table 1. Mechanical properties of BOF steel slag and granite.

\begin{tabular}{|c|c|c|c|c|}
\hline Type & Properties & BOF steel slag & Granite & Requirements \\
\hline \multirow{4}{*}{ Coarse aggregate } & Apparent specific gravity $\left(\mathrm{g} / \mathrm{cm}^{3}\right)$ & 3.7 & 2.9 & $\geq 2.6$ \\
\hline & LA Abrasion $(\%)$ & 13 & 17 & $\leq 28$ \\
\hline & Polished stone value & 68 & 52 & $\geq 42$ \\
\hline & Water absorption (\%) & 1.2 & 0.8 & $\leq 2$ \\
\hline Fine aggregate & Sand equivalent value (\%) & - & 70 & $\geq 60$ \\
\hline
\end{tabular}

\subsection{Specimen preparation}

The optimum binder content of asphalt mixes was determined by standard Marshall testing [11]. The aggregate with the maximum particle size of $13.2 \mathrm{~mm}$ was selected for continuous dense gradation design. The grading design of asphalt mixes is carried out by replacing granite coarse aggregate $(\geq 2.36 \mathrm{~mm})$ with equal volume of BOF steel slag. Five types of cylindrical
Marshall specimens with different BOF steel slag contents were prepared by impacting 75 times on each side, including one granite control group $(\mathrm{H})$ and four experimental group (S25, S50, S75, S100), using BOF steel slag to replace granite coarse aggregate in different proportion. Marshall testing results of mixes containing various amounts of BOF were shown in table 2 . The test results are satisfied with the requirements of Chinese specification [12].

Table 2. Volumetric properties of mixes containing various amounts of BOF steel slag

\begin{tabular}{ccccccc}
\hline Items & $\mathrm{H}$ & $\mathrm{S} 25$ & $\mathrm{~S} 50$ & $\mathrm{~S} 75$ & $\mathrm{~S} 100$ & Specification \\
\hline Optimum binder content (\%) & 4.7 & 4.6 & 4.4 & 4.3 & 4.2 & - \\
Density $\left(\mathrm{g} / \mathrm{cm}^{3}\right)$ & 2.5 & 2.6 & 2.7 & 2.9 & 3.0 & - \\
Marshall stability (KN) & 17.9 & 18.2 & 20.3 & 20.9 & 19.3 & $\geq 8$ \\
Marshall flow(mm) & 2.6 & 2.8 & 2.7 & 2.7 & 2.8 & $1.5 \sim 4$ \\
Air voids (\%) & 4.0 & 4.1 & 4.1 & 4.3 & 4.3 & $4 \sim 6$ \\
Voids in mineral aggregates (\%) & 14.3 & 14.9 & 14.7 & 14.3 & 14.3 & $\geq 14$ \\
Voids filled with asphalt (\%) & 71 & 73 & 72 & 70 & 70 & $65 \sim 75$ \\
\hline
\end{tabular}

According to the optimal asphalt binder content of asphalt mixes with different BOF steel slag content, this study prepared five kinds of rutting slab specimens $(300 \mathrm{~mm} \times 300 \mathrm{~mm} \times 50 \mathrm{~mm})$ according to the rutting test method. Totally 15 rutting slab specimens were prepared in this test. All specimens were mixed at $180^{\circ} \mathrm{C}$ and compacted at $110^{\circ} \mathrm{C}$, and cooled at room temperature for at least 48 hours before being fixed to the circular track where the CVS operated.

\section{Experimental program}

This study designed an experimental device to evaluate the function of pavement surface, called the CVS. A photo of the CVS machine is presented in Fig. 1. The CVS used four pneumatic tires with a diameter of 61.5 $\mathrm{mm}$ and a width of $195 \mathrm{~mm}$ to polish the test specimens. The slip rate between the tire and the specimen surface was $4.3 \%$. The test specimen was fixed to a circular orbit having a diameter of $8 \mathrm{~m}$. In this test, the vertical load of the tire is $40 \mathrm{KN}$ which is similar to the passenger car, and the load can be adjusted by the dump weight. The four tires are fixed in the arms which have hinge joints with the central rotary table.

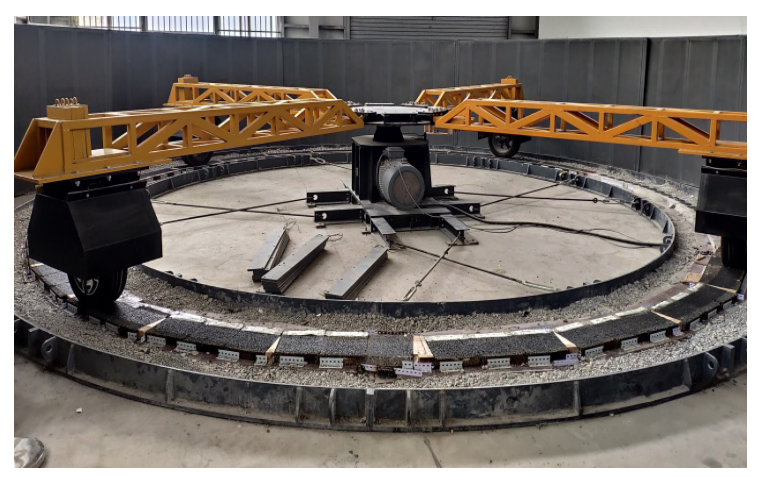

Fig. 1. Circular Vehicle Simulator

\section{Results and discussion}

Figs. 2 show the texture situation of BOF steel slag and granite after different loading times. Figs. 2 a), b), c), d) are the photos of BOF steel slag and the others are the photos of granite. Fig. 3 shows the relationship between loading times and British Pendulum Number (BPN). As shown in Fig. 3, the skid resistance attenuation laws of five mixes are basically similar, which can be divided 
into two phases: the attenuation phase (0-200 000 times loading) and the equilibrium stability phase (after 200 000 times loading). Due to the polishing and compacting of the aggregate, the BPN decreased greatly at the beginning of the attenuation phase, and the attenuation rate was fast. About 30000 times of loading, as the asphalt coating gradually polished from the aggregate surface, the coarse and fine texture of the mixes surface gradually became prominent, which made the BPN of the specimen increased slightly. Surface changes of BOF steel slag and granite are shown in Figs. 2 a), e). After the asphalt coating was completely removed, the aggregate began to be polished, and the BPN of the specimen continued to decrease at a slower speed. The changes in this process are shown in Figs. 2 b), c), f), g). When the BPN reached a certain number, the attenuation speed slowed down, and the line gradually tended to be parallel, which means the phase of equilibrium and stability has

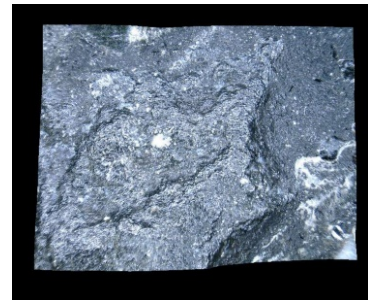

a) 30000 loading times

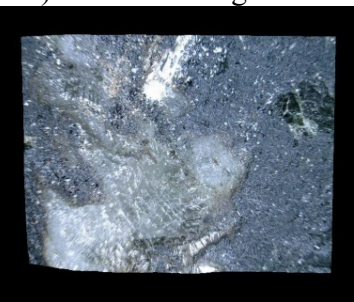

e) 30000 loading times

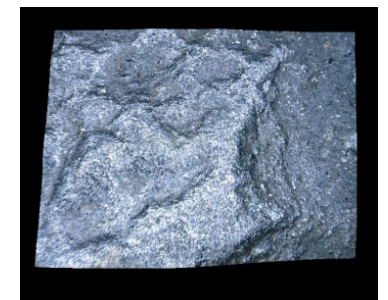

b) 100000 loading times

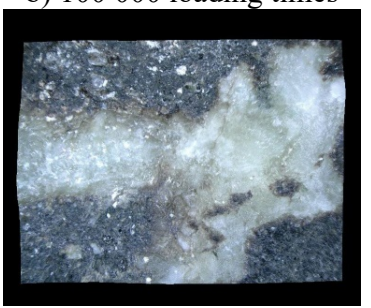

f) 100000 loading times been reached. In Figs. 2 d), h), the change of aggregate surface texture is gradually decreasing. As shown in Fig. 3 , the skid resistance value of mixes fluctuated slightly in the attenuation phase, and the fluctuation period of the mixes with different BOF steel slag content was different The former is mainly due to the following reason. As the asphalt film of aggregate surface was polished, coarse aggregate exposed to the tire. The skid resistance of aggregate surface was greater than that of the polished asphalt film. The latter can be explained by the reason that BOF steel slag has stronger adhesion to acidic asphalt binder compared with acid granite due to its porosity and alkalinity, which results the polishing speed of asphalt film on the mixes surface with more BOF steel slag was slower. Thus, the rise period of friction value, caused by the exposure of aggregate, was different for the mixes with different BOF steel slag contents.

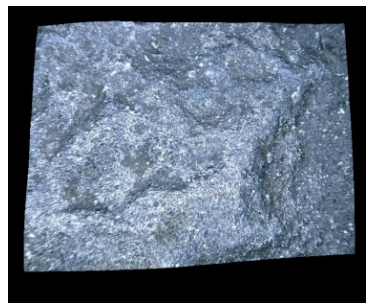

c) 200000 loading times

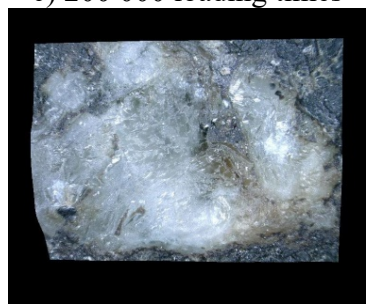

g) 200000 loading times

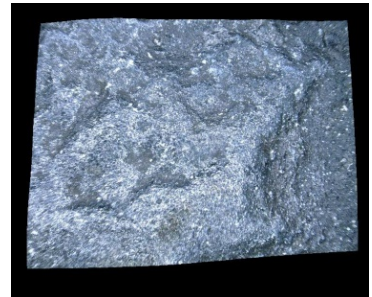

d) 400000 loading times

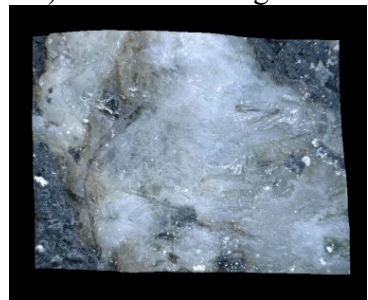

h) 400000 loading times

Fig. 2. Loading times of BOF steel slag and granite

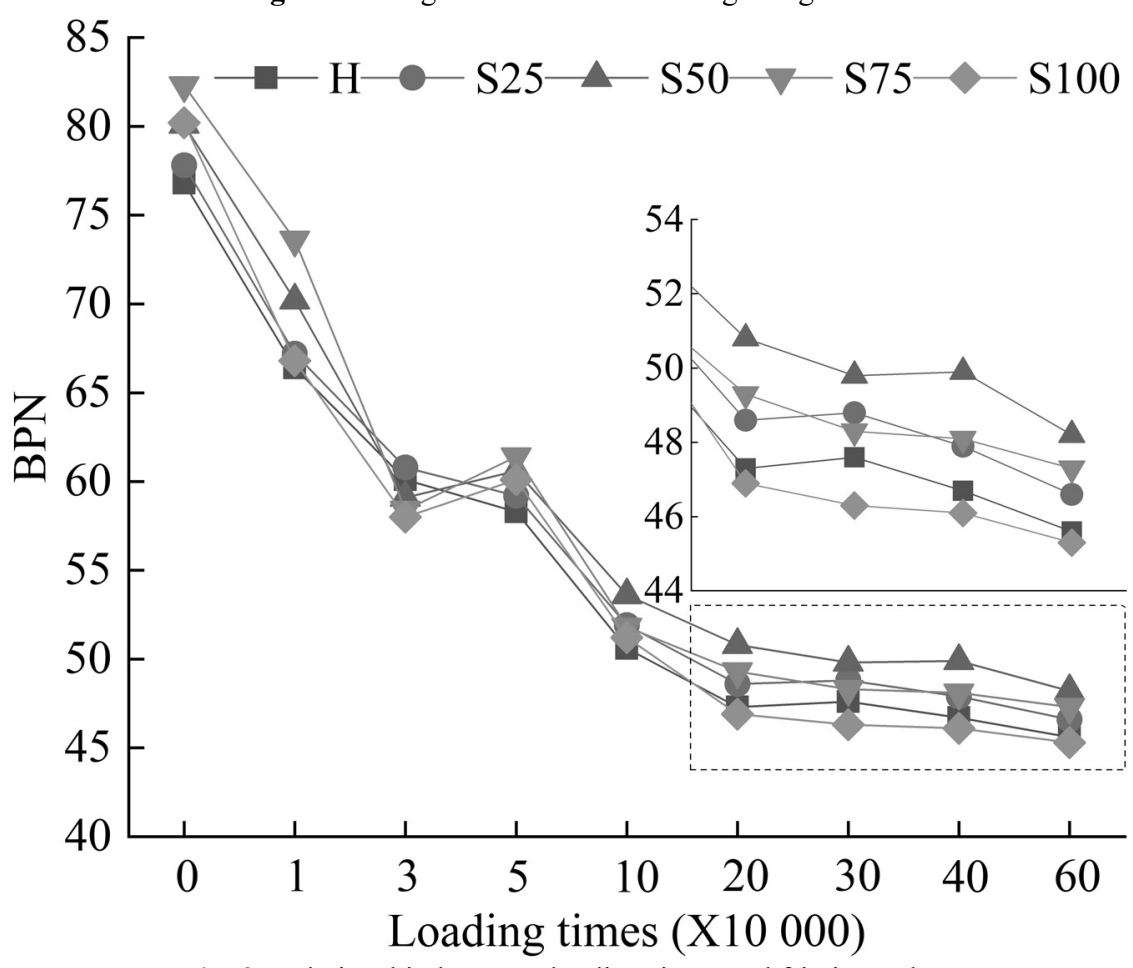

Fig. 3. Relationship between loading times and friction value 
As shown in Fig. 3, during 200000 loading times to 600000 loading times, after 200000 times of loading, the mean BPN of $\mathrm{H}, \mathrm{S} 25, \mathrm{~S} 50, \mathrm{~S} 75$ and $\mathrm{S} 100$ were respectively $46.8,48.0,49.7,48.2,46.2$. So, the anti-skid attenuation rate of mixes was arranged from large to small in sequence: $\mathrm{S} 50>\mathrm{S} 75>\mathrm{S} 25>\mathrm{H}>\mathrm{S} 100$. Replacing $50 \%$ of the volume of coarse aggregate with BOF steel slag in asphalt mixes had a good effect on improving its long-term skid resistance. This is because BOF steel slag and granite formed a different abrasion in the process of loading. The wear and polish resistance of BOF steel slag are much more important than that of granite, which leads to the differential polishing under the same loading and polishing, as shown in the Fig. 4. A height difference appears on the surface of the aggregate to make the new texture complicated, which improves the skid resistance of the mixes.

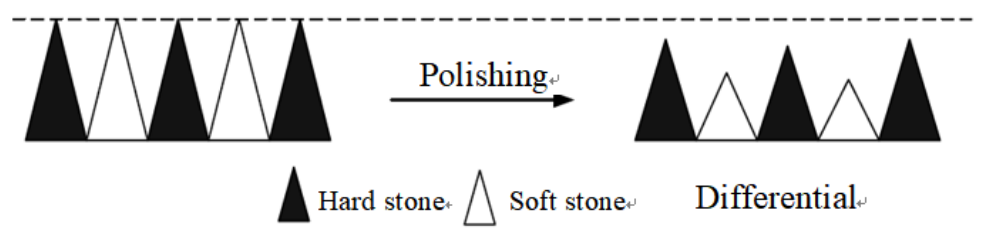

Fig. 4. The differential polishing mechanism

\section{Conclusion}

The major conclusions of this study are as follows:

(1) A CVS test system was developed. This system overcomes the limitations of the existing equipment and can simulate the polishing effect of wheels on real road surface to ensure the validity of the experimental results.

(2) The BOF steel slag is a good resource for asphalt mixture. BOF steel slag has better soundness, polished value and abrasion resistance than granite.

(3) The skid resistance test results show that S50 had the lowest anti-skid attenuation rate and the best long-term skid resistance, followed by S75, S25, H and S100.

\section{Acknowledgments}

This research is supported by National key Research and development Program of China, China (No. 2018YFB1 600200); the Fundamental Research Funds for the Centr al Universities, Chang'an University, China (No. 300102 219502).

\section{References}

1. A. Lbrahim, Q. Hisham, S. Faisal, Civ Eng. 34 (2008)

2. Liu, Q. T., Li, B., Schlangen, E., Sun, Y. H., Wu, S. P. APPL SCI-BASEL, 7(10) (2017)

3. PG. Roe, Basic Oxygen steel slag as Surface Course Aggregate: An Investigation of Skid Resistance (TRL REPORT TRL, 2003)

4. A. F. Stock, C. M. Ibberson, I. F. Taylor, TRANSPORT RES REC. 1545, 35-40 (1996)

5. Shen, D. H. Wu, C. M. Du, J. C. CONSTR BUILD MATER. 23(1): 453-461(2009)

6. Qian, Z. D. Liu, Y. Liu, C. B. Zheng, D. CONSTR BUILD MATER. 114 (2016).

7. Wang, D. Xie, X. M. Oeser, B. Steinauer, Airfield and Highway Pavements (Amer Society of Civil Engineers, 2015)
8. A. K. Mohammad, ROAD MATER PAVEMENT. 17:1-17 (2016)

9. Chen, X. H. D, S. B. G, Y. Q. J TEST EVAL. 44(2): 885-894 (2016)

10. Shen, J. A. Li, F. P. Niu, K. M. Xia, L. L. Liu, Q. Q. Chen, J. Test Methods of Aggregate for Highway Engineering (Chinese Communications, Beijing, 2005).

11. Standard Test Method for Marshall Stability and Flow of Asphalt Mixtures, (ASTM, 2015).

12. Shen, J. A. Li, F. P. Chen, J. Technical Specifications for Construction of Highway Asphalt Pavements, (Chinese Communications, Beijing, 2004) 